\title{
Synchrotron Radiation Effects on Catalytic Systems As Probed with a Combined In-Situ UV-Vis/XAFS Spectroscopic Setup
}

\author{
J. Gerbrand Mesu, Ad M. J. van der Eerden, Frank M. F. de Groot, and \\ Bert M. Weckhuysen* \\ Department of Inorganic Chemistry and Catalysis, Debye Institute, Utrecht University, \\ Sorbonnelaan 16, 3584 CA Utrecht, The Netherlands
}

Received: October 20, 2004; In Final Form: December 13, 2004

\begin{abstract}
UV-vis spectroscopy was used in a combined in-situ UV-vis/XAFS spectroscopic setup to study the synchrotron radiation effect on aqueous homogeneous copper solutions. Two different systems were studied. In the first study, the focus was on a copper bipyridine-catalyzed oxidation of benzyl alcohol to benzaldehyde with 2,2,6,6- tetramethylpiperidinyl-1-oxy and base as cocatalysts. It was found that when the reaction mixture is exposed to the X-ray beam, the features present in the in-situ UV-vis spectrum develop differently compared to the situation when the reaction mixture is not exposed to the X-ray beam. Besides a temperature effect of the X-ray beam, both the UV-vis analysis and the XAFS analysis showed a reducing influence of the X-ray beam on the sample. To investigate this in more detail, we studied a series of dilute aqueous copper solutions from different precursor salts, viz., $\mathrm{Cu}\left(\mathrm{NO}_{3}\right)_{2} \cdot 3 \mathrm{H}_{2} \mathrm{O}, \mathrm{CuSO}_{4} \cdot 5 \mathrm{H}_{2} \mathrm{O}, \mathrm{CuCl}_{2}$, and $\mathrm{CuBr}_{2}$. It was found that the different aqueous copper solutions have different stabilities under the influence of the X-ray beam. Especially the solution from the $\mathrm{CuCl}_{2}$ precursor salt was found to be unstable and to be subjected to reduction. These examples illustrate the need for a second technique, such as in-situ UV-vis spectroscopy, to evaluate the effect of synchrotron radiation used to measure in-situ XAFS on catalytic systems.
\end{abstract}

\section{Introduction}

In catalysis there is an increasing trend in using in-situ spectroscopic techniques to elucidate the reaction mechanism of a catalytic process as well as attempts to identify the active site and the associated reaction intermediates. ${ }^{1-5}$ Since each species has a specific spectroscopic fingerprint, it has been shown that such reaction mechanisms can only be built up by making use of multiple characterization techniques. Because of the need for a multitechnique approach, it is not surprising that scientists in recent years have tried to combine two characterization techniques in one reaction setup. Examples are XRD/ $\mathrm{XAFS},{ }^{6-9} \mathrm{XAFS} / \mathrm{UV}-\mathrm{vis},{ }^{10,11} \mathrm{UV}-\mathrm{vis} / \mathrm{Raman},{ }^{12-15}$ and UVvis/EPR. ${ }^{16-18}$ Thus, complementary information about the catalytic system can be obtained at the same time and measured under identical process conditions guaranteeing the validity of the measured species for building up the reaction scheme. ${ }^{19}$

The goal of this paper is to show that there is an additional advantage of performing combined in-situ spectroscopy on catalytic systems. It is known that high-intensity light sources, such as laser light, UV light, and synchrotron radiation, may influence the state of the catalyst and its reaction medium, ranging from sample heating, changing oxidation-reduction behavior, up to even the destruction of the active site. ${ }^{20-22}$ One way to track such changes is by making use of a second spectroscopic technique attached to the reaction vessel. In this work, we will show the advantages of an in-situ UV-vis/EDXAFS setup for probing the state of the catalyst material in the presence and absence of a synchrotron X-ray beam. For this purpose, we have selected two systems. The first system is the oxidation of benzyl alcohol, using a copper bipyridine complex

* Corresponding author. Phone: + 31-30-2534328. Fax: +31-302511027. E-mail: b.m.weckhuysen@chem.uu.nl. in a water/NMP mixture (1:1), with 2,2,6,6- tetramethylpiperidinyl-1-oxy (TEMPO) and base as cocatalysts. The second system is an aqueous copper solution from different copper precursor salts. Although sometimes ignored in the field of catalysis, we will show that, depending on the reaction mixture composition as well as on the catalyst system under investigation, unexpected effects may occur which otherwise would have been unnoticed when only the in-situ XAFS technique would have been applied.

\section{Experimental Methods}

Solutions and Reactions. The oxidation of benzyl alcohol was carried out in a $\mathrm{NMP} / \mathrm{H}_{2} \mathrm{O}(1: 1)$ solvent mixture at room temperature. For the reaction to occur, four different solutions were mixed: a $60 \mathrm{mM} \mathrm{CuBr} /$ /bipyridine (1:1) solution, a 60 $\mathrm{mM}$ benzyl alcohol solution, a $60 \mathrm{mM}$ 2,2,6,6-tetramethylpiperidinyl-1-oxy (TEMPO) solution, and a $60 \mathrm{mM}$ TEAOH solution. The four solutions were mixed in a 1:1:1:1 ratio, resulting in a $15 \mathrm{mM}$ copper concentration in the cuvette. The NMP ( $N$-methylpyrrolidone) solvent (Biosolve), $\mathrm{CuBr}_{2}$ (Acros, 99\%+), bipyridine (Acros, 99+\%), benzyl alcohol (Aldrich, $99+\%$ ), TEMPO (Acros, 98\%), and 20 wt \% TEAOH in $\mathrm{H}_{2} \mathrm{O}$ (Acros) were used without further purification. The concentration of the copper bipyridine $(1: 1)$ complex in $\mathrm{NMP} / \mathrm{H}_{2} \mathrm{O}(1: 1)$ for the stability experiments was $60 \mathrm{mM}$. The UV-vis/EDXAFS experiments on the aqueous copper solutions were performed on both 10 and $60 \mathrm{mM}$ solutions from different copper precursor salts: $\mathrm{Cu}\left(\mathrm{NO}_{3}\right)_{2} \cdot \mathrm{H}_{2} \mathrm{O}, \mathrm{CuSO}_{4} \cdot 5 \mathrm{H}_{2} \mathrm{O}, \mathrm{CuCl}_{2}$ (all from Merck, p.a.), and $\mathrm{CuBr}_{2}$ (Acros, 99\%+).

Characterization and UV-Vis/ED-XAFS Setup. The UVvis/ED-XAFS data were measured at the undulator beam line ID24, at the ESRF (Grenoble, France). A specially designed 

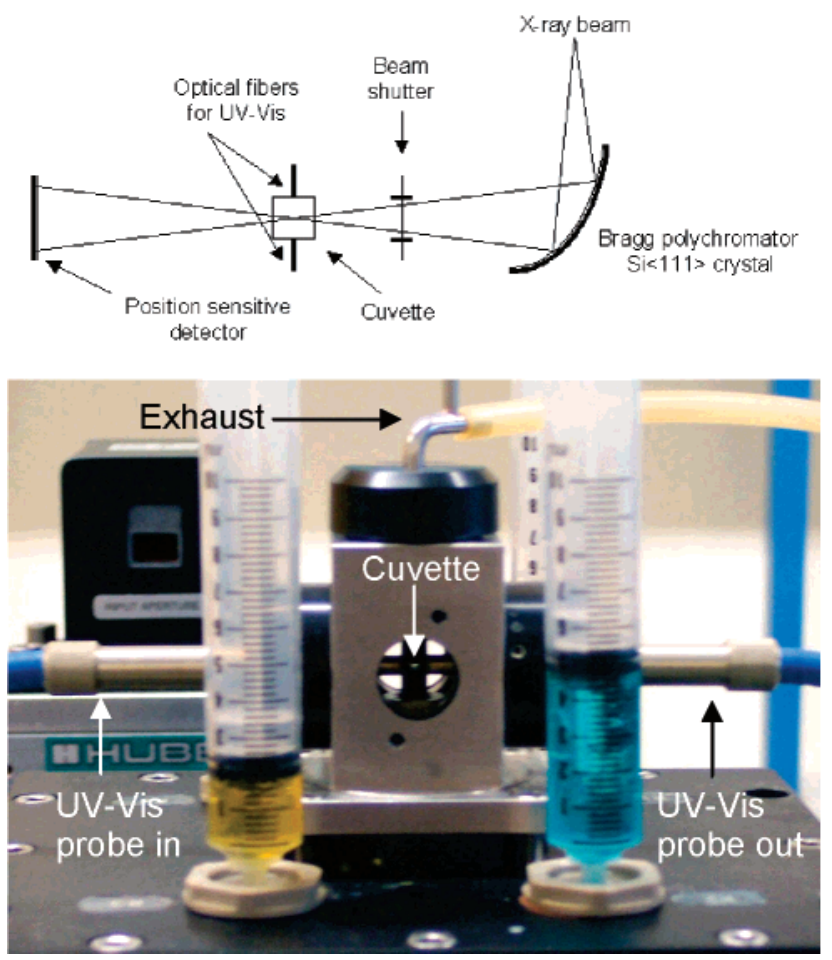

Figure 1. Schematic top-view representation of setup (a) and picture (b) of the cuvette in the observation head on top of the stopped-flow module (SFM), seen in the direction of the X-ray beam. The optical fibers for the UV-vis can be seen on the left and the right, as well as the syringes used to fill the SFM. Back in the left is the beam shutter, and on top is the exhaust pipe.

setup was used (for a schematic overview, see Figure 1). The solutions were brought into a specially designed black quartz cuvette using the commercially available Bio-logic stoppedflow module (SFM-400). The cuvette has a path length in both $\mathrm{X}$-ray and UV-vis directions of $5 \mathrm{~mm}$ and a total sample volume of $80 \mu \mathrm{L}$. The transparent quartz windows in the X-ray direction have a thickness of $100 \mu \mathrm{m}$, as to minimize the X-ray absorption of the windows at the energy of the copper edge. To protect the sample from heating and degradation by the high photon flux of X-rays $\left(10^{12}\right.$ photons $\left.\mathrm{s}^{-1}\right)$, a beam shutter was placed in front of the sample. The shutter is opened only when $\mathrm{X}$-ray absorption measurements are performed. The spot size of the X-ray beam in the focal spot in the sample is $0.03 \times 0.2$ $\mathrm{mm}^{2}(\mathrm{H} \times \mathrm{V}$, fwhm).

The XAFS data were collected using a phosphorus-masked Peltier cooled Princeton CCD camera. The X-rays were focused on the sample using a curved $\mathrm{Si}(111)$ Bragg polychromator crystal. The UV-vis spectra (in the range $200-735 \mathrm{~nm}$ ) were collected in transmission, perpendicular to the incident X-ray beam, using a MMS-UV1/500-1 high-speed diode spectrometer equipped with optical fibers. This spectrometer is able to collect a complete UV-vis absorption spectrum in $0.8 \mathrm{~ms}$.

For the oxidation of benzyl alcohol, every $9.5 \mathrm{~s}$ a new XAFS spectrum was recorded. The first $8 \mathrm{~s}$ are for the collection of the XAFS data, followed by $1.5 \mathrm{~s}$ for the read-out of the data. During this read-out period the beam shutter is closed. In this way, 25 XAFS spectra were collected in time, covering the first $4 \mathrm{~min}$ of the reaction. This procedure was repeated 15 times to improve the signal-to-noise ratio of the XAFS data.

The $\mathrm{Cu}$ K-edge XAFS spectra on $10 \mathrm{mM}$ aqueous copper solutions from different precursor salts were collected at the Dutch-Belgian beam line (DUBBLE), at BM26A of the European Synchrotron Radiation Facility (ESRF), Grenoble,
France. The measurements were performed at room temperature with a Si(111) double crystal monochromator. The liquid samples were measured in stainless steel cells (diameter of 2.5 $\mathrm{mm}$ ) with Kapton windows. The spot size on the sample is 0.5 $\times 0.5 \mathrm{~mm}^{2}(\mathrm{H} \times \mathrm{V}$, fwhm $)$, with a photon flux of $10^{11}$ photons $\mathrm{s}^{-1}$. The XAFS spectra were collected in the fluorescence mode, in a 90-degree orientation to the incident X-ray beam, using a nine-channel monolithic germanium detector. The time to record one complete XAFS spectrum is $45 \mathrm{~min}$.

TEM images were obtained with a Fei Technai 20 FEG TEM operating at $200 \mathrm{kV}$. The samples were, after centrifugal treatment and resuspension in water, dispersed by making use of a glow-discharge-pretreated, copper-grid-supported, holey carbon film.

\section{Results and Discussion}

Oxidation of Benzyl Alcohol. The combination of the UVvis and the ED-XAFS techniques was used with the intention of studying the mechanism of the oxidation of benzyl alcohol to benzaldehyde using a copper bipyridine $(1: 1)$ complex in the presence of TEMPO and base as cocatalysts. The catalytic activity was found to be higher when using $\mathrm{CuBr}_{2}$ as precursor salt for the $\mathrm{Cu}$ bipyridine solution (compared to the $\mathrm{CuCl}_{2}$ and $\mathrm{Cu}\left(\mathrm{NO}_{3}\right)_{2}$ precursor salts). ${ }^{23} \mathrm{~A} \mathrm{Cu}(\mathrm{I})$ species is proposed to be an intermediate in the mechanism of the reaction. ${ }^{23} \mathrm{UV}-$ vis and XAFS spectroscopy are both techniques that are very capable of showing changes in the oxidation state of copper. In $\mathrm{UV}-$ vis, $\mathrm{Cu}(\mathrm{II})\left(\mathrm{d}^{9}\right)$ has a d-d transition in the region of $600-$ $800 \mathrm{~nm}$, whereas in $\mathrm{Cu}(\mathrm{I})\left(\mathrm{d}^{10}\right)$ this $\mathrm{d}-\mathrm{d}$ transition is not present. In XAFS spectroscopy $\mathrm{Cu}(\mathrm{I})$ (and also $\mathrm{Cu}(0)$ ) are characterized by a preedge feature in the $8980-8985 \mathrm{eV}$ area of the XANES of the copper edge. This feature is not present for $\mathrm{Cu}(\mathrm{II}) .{ }^{24}$ The combination of the two techniques can be very informative in the study of changes in the oxidation state of a copper system.

First, the propagation of the oxidation reaction of benzyl alcohol was monitored by UV-vis spectroscopy alone. The development of the first 4 min of the reaction is shown in Figure 2a. Around $420 \mathrm{~nm}$, a band is developing in time, which can be assigned to a metal-to-ligand charge-transfer transition in a $\mathrm{Cu}$ (I) species. ${ }^{25}$ The development of the intensity of this band in time is shown in Figure 3a. However, when the UV-vis spectrum is recorded with the reaction mixture exposed to the $\mathrm{X}$-ray beam (Figure 2b), the development of this band in time is much faster (Figure 3b). What also attracts attention is the repetitive pattern that is visible in the development of the 420 $\mathrm{nm}$ band. This pattern is absent when there is no X-ray beam on the sample. The origin from this pattern is the closing of the beam shutter, which is closed for $1.5 \mathrm{~s}$ after each XAFS measurement for data read-out. In these $1.5 \mathrm{~s}$, the intensity of the UV-vis absorption band is decreasing. After the opening of the beam shutter for the next XAFS measurement, the absorption starts to rise again. This gives a clear indication that the X-ray beam is influencing the reaction mixture in the cuvette.

The explanation for the difference in the UV-vis absorption spectra with and without the $\mathrm{X}$-ray beam on the reaction mixture could be a temperature effect that the X-ray beam has on the sample. The reaction mixture is heated in the plane of the dispersive X-ray beam, which speeds up the complex formation and/or catalytic activity. As soon as the beam shutter is closed, the heating stops and the heat and/or complexes in the plane of the X-ray beam start to exchange with the rest of the reaction mixture, which is not in the plane of the beam. This causes a decrease in the absorption in the UV-vis spectrum in the 1.5 $s$ the beam shutter is closed and gives rise to the saw-tooth pattern in Figure 3b. 

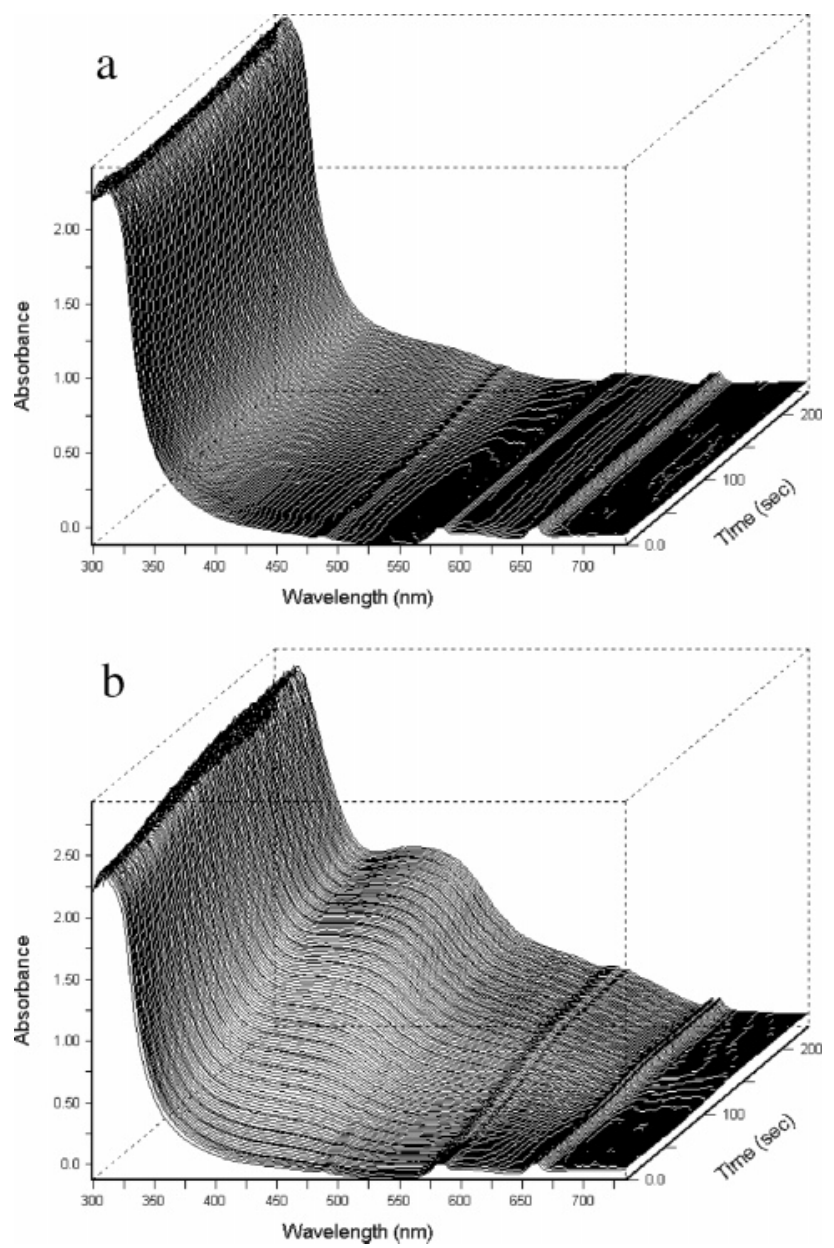

Figure 2. UV-vis absorption spectra of the oxidation reaction of benzyl alcohol to benzyl aldehyde using copper bipyridine as catalyst and TEMPO and base as cocatalysts (a) without and (b) with the X-ray beam on the sample.

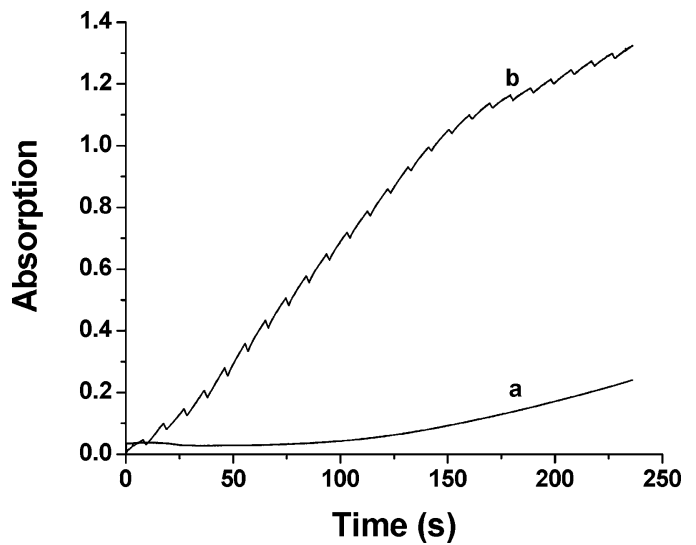

Figure 3. Evolution of the band at $420 \mathrm{~nm}$ in the UV-vis spectrum in time for the oxidation of benzyl alcohol to benzaldehyde using copper bipyridine as catalyst and TEMPO and base as cocatalysts: (a) without the beam, and (b) with the X-ray beam.

To check this hypothesis, the temperature of the reaction mixture in the cuvette (out of the plane of the X-ray beam) was checked. It was found that as soon as the beam shutter was opened, the temperature of the reaction mixture instantaneously increased by about one degree Celsius, after which it stabilized. After the closing of the beam shutter, the temperature decreased within a few seconds back to its original value. This indicates that there is a temperature effect of the X-ray beam on the

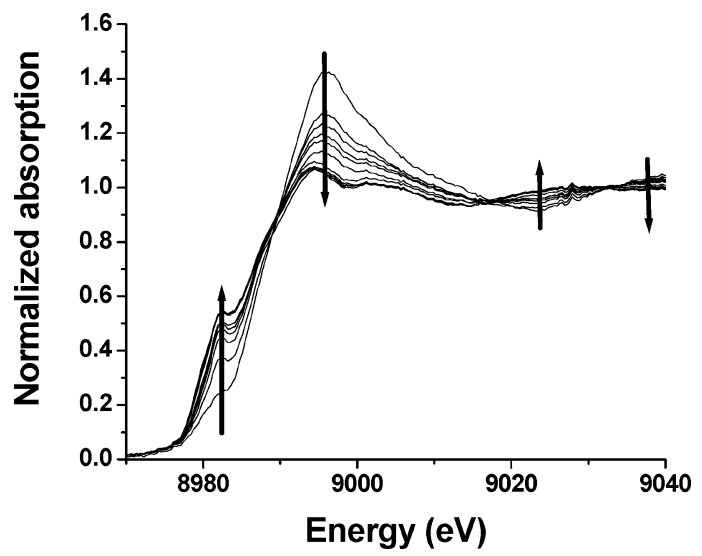

Figure 4. X-ray absorption spectra of the first $4 \mathrm{~min}$ of the oxidation of benzyl alcohol to benzaldehyde. The time between two consecutive absorption spectra is $9 \mathrm{~s}$. The trends in time are indicated with the arrows.

sample, an effect that will be quite large in the plane of the $\mathrm{X}$-ray beam.

To quantify this effect, the radiation dose per second on the sample was calculated. ${ }^{21,26}$ This value was used to calculate the energy release per second in the volume of the X-ray beam. Together with the value for the heat capacity of the solvent, this gave a temperature rise in the volume of the plane of the $\mathrm{X}$-ray beam of $14{ }^{\circ} \mathrm{C} / \mathrm{s}$. These theoretical calculations give proof that the temperature in the cuvette can locally be quite high. This can be a possible explanation for the increased speed in the upcoming of the $420 \mathrm{~nm}$ band when the sample is exposed to the X-ray beam. If this heating would be the only effect of the X-ray beam on the sample (provided it is not too much), the data could still be used for analysis of the species involved in the reaction mechanism.

However, there can be an additional explanation for the observed differences. The X-ray absorption spectra of the first 4 min of the reaction (with a 9-s time resolution) are shown in Figure 4. Very large changes in the X-ray absorption spectra are occurring in the first minute of the reaction (indicated with arrows). A preedge feature in the region $8980-8985 \mathrm{eV}$ of the XANES area is coming up (typical for $\mathrm{Cu}(\mathrm{I})$, but also for $\mathrm{Cu}$ $(0)$ ), and the white line intensity is going down strongly. These changes suggest that reduction of the copper is occurring. Besides that, the features in the EXAFS region are changing completely. At first sight nothing strange is happening, the species participating in the oxidation reaction are probed and the XAFS results suggest the formation of a $\mathrm{Cu}(\mathrm{I})$ intermediate. In the last $3 \mathrm{~min}$ of the reaction, only minor changes occur in the development of a feature at 8979-8980 eV. However, based on the increase of the XANES feature around $8979 \mathrm{eV}$ in time and the evolution of the features present in the EXAFS to features present in a copper foil (Figure 5), the formation of $\mathrm{Cu}(0)$ is suggested. ${ }^{27}$

To determine what is happening in the reaction mixture, the copper system was studied without catalysis. Therefore the copper bipyridine solution was measured without substrate and cocatalysts. Without the X-ray beam, the copper bipyridine (1: $1)$ in water/NMP (1:1) is stable in time, there are no changes in the UV-vis absorption in time. However, when this solution is exposed to the X-ray beam, it is no longer stable. The absorption in the UV-vis starts to increase over the total wavelength range, and features around 460 and $540 \mathrm{~nm}$ start to develop (Figure 6). Analysis of the X-ray absorption spectra showed that all the changes that are visible in the X-ray absorption spectra are exactly the same as those for the complete 


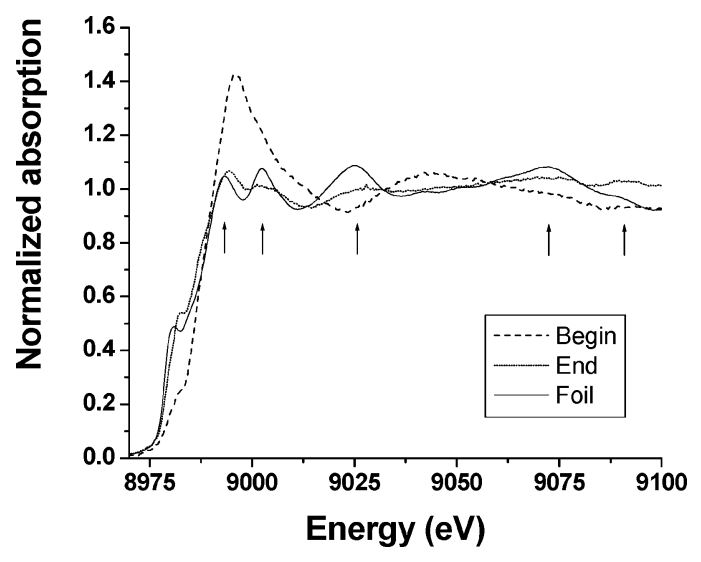

Figure 5. The X-ray absorption spectrum of the copper foil compared to the absorption spectrum of the sample after $4 \mathrm{~min}$. The arrows indicate the reproduced features in the EXAFS. The X-ray absorption spectrum at the beginning of the reaction is also shown.

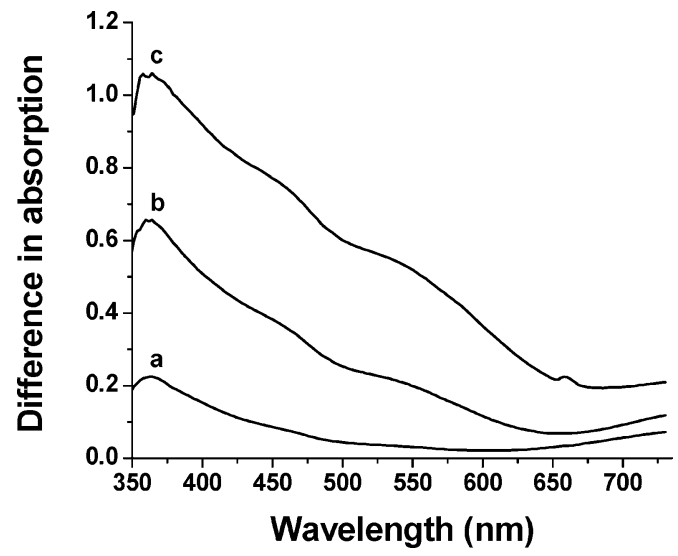

Figure 6. The difference in the absorption in the UV-vis spectra with respect to the absorption before the X-ray beam was on the copper bipyridine solution, after (a) $100 \mathrm{~s}$, (b) $200 \mathrm{~s}$, and (c) $300 \mathrm{~s}$ of the $\mathrm{X}$-ray beam on the sample.

reaction mixture. These results show that the X-ray beam also has a strong reducing effect on the sample and support the hypothesis about the formation of colloidal copper. It is also confirmed by the UV-vis results: the increase in absorption in the UV-vis spectra in time is caused by the formation of colloidal copper, which causes a decrease in transmission of the sample. This process will also be the reason for the increased speed of development of the 420-nm band in Figure 3. The absorption of the colloidal particles is superposed on the absorption of the catalytic species in the 420-nm area.

So the study of the oxidation reaction in the UV-vis/EDXAS setup shows that two processes are occurring at the same time in the cuvette. Within the plane of the X-ray beam mainly the reduction/heating process occurs, whereas in the rest of the cuvette mainly the normal catalysis reaction takes place, only influenced by the temperature effect of the X-ray beam. With the UV-vis technique a superposition of both processes is probed, because the area probed by the UV-vis technique in the cuvette is much larger than the plane of the X-ray beam (ratio of about 500:1). So the largest part of the species that is probed by UV-vis will be the one that participates in catalysis. However, all the species that are probed by the XAFS technique have been exposed to the X-ray beam, so the X-ray absorption spectra will show more the effect the X-ray beam has on the sample.

Of course it is possible that the reducing influence of the $\mathrm{X}$-ray beam is facilitated or even caused by the presence of the

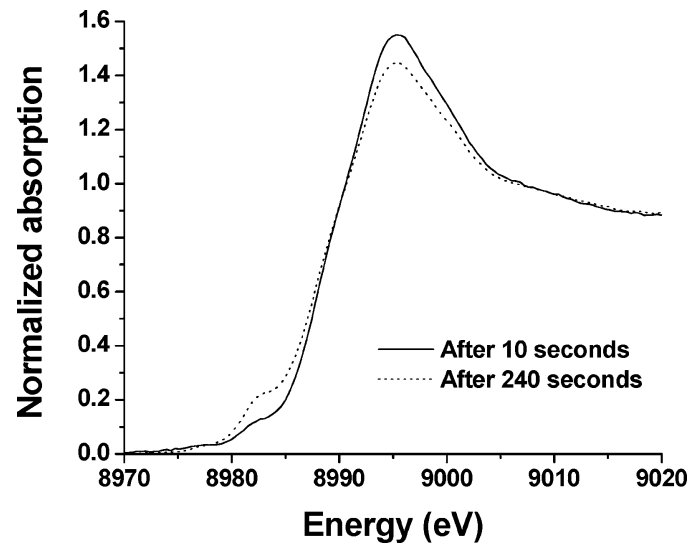

Figure 7. XANES of the $60 \mathrm{mM}$ aqueous $\mathrm{CuCl}_{2}$ solution after $10 \mathrm{~s}$ and after $240 \mathrm{~s}$.

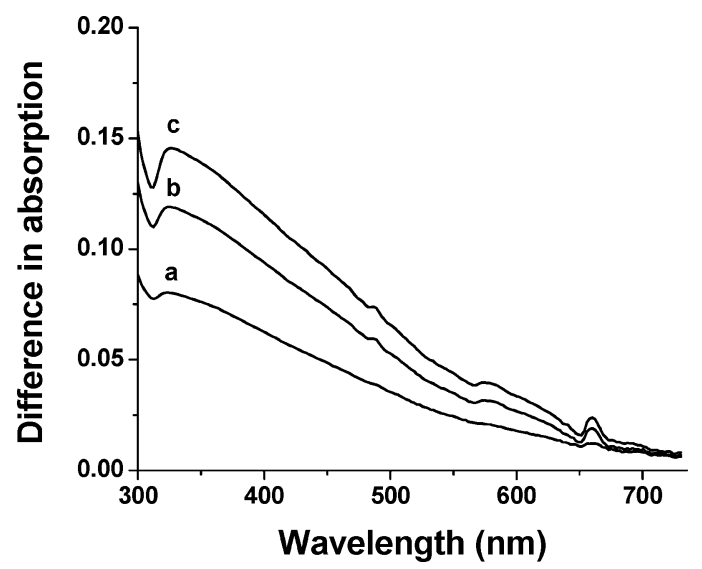

Figure 8. The difference in the UV-vis absorption spectrum with respect to a solution that not has been exposed to the X-ray beam, (a) $80 \mathrm{~s}$, (b) $160 \mathrm{~s}$, and (c) $240 \mathrm{~s}$ after the solution is exposed to the X-ray beam.

bipyridine ligand. Therefore, we studied the influence of the $\mathrm{X}$-ray beam on aqueous copper solutions from different precursor salts, to check whether the same processes are occurring to the copper under the influence of the X-ray beam, without the presence of a chelating ligand.

Stability of Aqueous Copper Solutions. The stability of aqueous copper solutions from four different $\mathrm{Cu}$ (II) precursor salts under the influence of the $\mathrm{X}$-ray beam was investigated. The solutions from the $\mathrm{CuSO}_{4} \cdot 5 \mathrm{H}_{2} \mathrm{O}$ and $\mathrm{Cu}\left(\mathrm{NO}_{3}\right)_{2} \cdot 3 \mathrm{H}_{2} \mathrm{O}$ precursor salts were exposed for $10 \mathrm{~min}$ in the cuvette and found to be stable under the influence of the dispersive X-ray beam. There was, however, a reducing effect on the solutions from $\mathrm{CuBr}_{2}$ and $\mathrm{CuCl}_{2}$, the effect being larger for the $\mathrm{CuCl}_{2}$ solution. The X-ray absorption spectra at the beginning and the end of the exposure time and the UV-vis spectra of the first $5 \mathrm{~min}$ of the exposure to the $\mathrm{X}$-ray beam of the $\mathrm{CuCl}_{2}$ solution are shown, respectively, in Figures 7 and 8. Again the $\mathrm{Cu}(\mathrm{I}) / \mathrm{Cu}(0)$ preedge feature is coming up and the white line is going down in time and the absorption in the UV-vis is increasing in time. So it seems that the presence of a halide is responsible for the reducing effect of the X-ray beam. Indeed, the process was found to be dependent on the halide concentration: the higher the halide concentration (by adding the sodium salt of the halide), the faster the development of the preedge feature in time and the faster the increase in absorption in the UV-vis absorption spectra.

To check the hypothesis of the formation of colloidal copper, one of the $60 \mathrm{mM} \mathrm{CuCl} 2$ solutions that had been exposed to the X-ray beam was studied with transmission electron micros- 


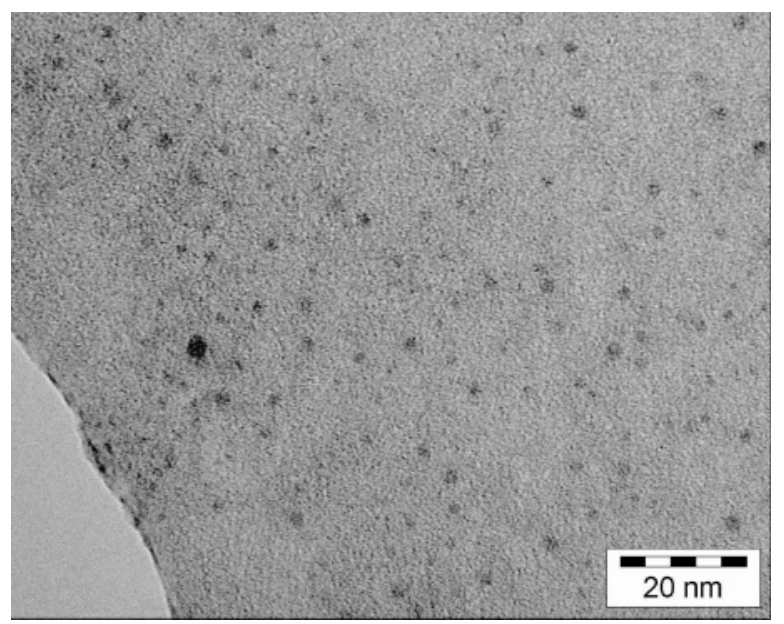

Figure 9. TEM image of the colloidal copper particles found in the aqueous $\mathrm{CuCl}_{2}$ solutions after synchrotron experiments. Most of the particles have a diameter of $2-3 \mathrm{~nm}$.

copy (TEM). The result is shown in Figure 9. In the sample the colloidal copper particles are clearly visible. The particle size distribution of the copper particles is quite homogeneousin the range of $2-3 \mathrm{~nm}$. These TEM results confirm the formation of the colloidal copper particles.

The UV-vis/ED-XAFS setup is designed to collect X-ray absorption spectra within seconds. To achieve this, all X-ray energies are focused on the sample at the same time. This makes the radiation dose, especially at the small focal spot in the sample $\left(0.03 \times 0.2 \mathrm{~mm}^{2}(\mathrm{H} \times \mathrm{V})\right)$ with a flux of $10^{12}$ photons $\mathrm{s}^{-1}$, very high. This dose is the reason for the very rapid formation of the colloidal copper particles. To test the influence of the flux, the stability experiments with the aqueous copper solutions were repeated at DUBBLE. The radiation dose in the larger focal spot $\left(0.5 \times 0.5 \mathrm{~mm}^{2}(\mathrm{H} \times \mathrm{V})\right)$ at this bending magnet beamline with a flux of $10^{11}$ photons s$^{-1}$ is $381 \mathrm{~J} / \mathrm{kg}$ in a total volume of $6.25 \times 10^{-10} \mathrm{~m}^{3}$. This value is much lower than on the ED-XAFS beam line ID-24, where the radiation dose is $41545 \mathrm{~J} / \mathrm{kg}$ in a volume of only $4.0 \times 10^{-11} \mathrm{~m}^{3}$. So if the flux of the incoming X-ray beam is responsible for the reducing influence, the reducing behavior is expected to be orders of magnitudes lower.

The different aqueous copper solutions were exposed to the $\mathrm{X}$-ray beam for several hours. It takes about 45 min to collect a qualitative good complete X-ray absorption spectrum. Although the radiation dose at DUBBLE is much lower, exactly the same trends in stability for the copper salts were found, only at a different time scale (Figure 10). The solutions from the sulfate and the nitrate salts are stable, and the copper solution from the $\mathrm{CuCl}_{2}$ salt is more susceptible to reduction than the $\mathrm{CuBr}_{2}$ salt. Again, increasing the chloride concentration also increased the speed of the reduction process. This indicates that lowering the radiation dose on a sample does not prevent radiation damage from occurring; it only slows down the process.

It is known that in aqueous solutions under influence of $\mathrm{X}$-rays, radiolysis of water can occur. ${ }^{27,28}$ This radiolysis process generates all kinds of species, like $\mathrm{OH} \cdot$ and $\mathrm{H} \cdot$ radicals, as well as species such as $\mathrm{OH}^{-}, \mathrm{H}^{+}$, and hydrated electrons. Usually recombination of the radiolysis products occurs. But when a scavenger takes away one of the products of the radiolysis process, this recombination process can no longer take place and accumulation of the products of radiolysis occurs. In this way, accumulation of the hydrated electrons also can occur. These hydrated electrons can reduce the copper cations to the

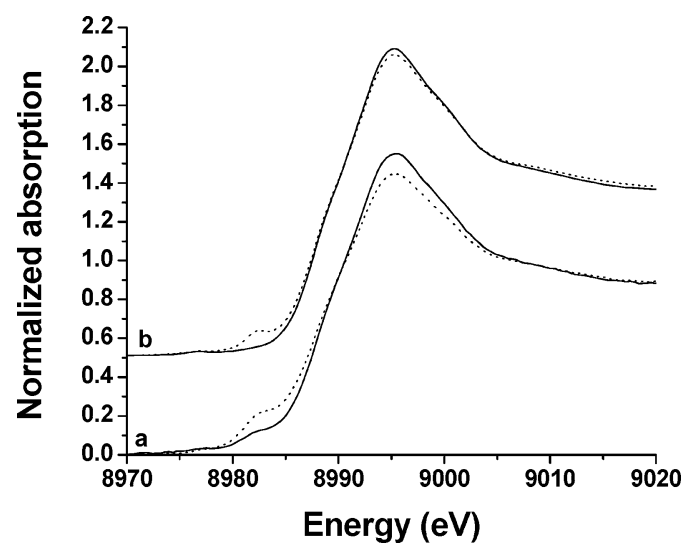

Figure 10. Comparison of the development in the X-ray absorption spectra at (a) ID24 after, respectively, 10 and $240 \mathrm{~s}$, and at (b) DUBBLE after, respectively, 45 and $225 \mathrm{~min}$.

metallic state. It is possible that a halide anion acts as a scavenger of one of the radiolysis products, allowing the hydrated electron concentration and the speed of reduction to increase. Another explanation can be that the nitrate and the sulfate anions act as scavengers for the hydrated electron, in that way protecting the copper cation from being reduced. The chloride and the bromide anions are much less capable of doing that.

One has to realize that every characterization measurement will, to a certain extent, perturb the sample under investigation; i.e., the sample can undergo modifications due to the probe used to obtain chemical information from the sample. More specifically, high-intensity light sources, such as X-ray light (e.g., in the case of XAFS measurements making use of synchrotron radiation sources) and UV light (e.g., in the case of Raman measurements making use of UV lasers), (1) are able to generate new species in the reaction mixtures (solvent, reagent, etc.) that can influence the processes and/or (2) can alter the molecular structure of the catalytic system under investigation. These effects can take place even at a low radiation doses; in other words, such effects can also take place at synchrotron light sources making use of bending magnets where the long exposure time may lead to a too high total light flux. This means that, for every X-ray absorption experiment, it should be evaluated whether an observed change in oxidation state originates from the reaction under study or is merely due to an influence of the $\mathrm{X}$-ray beam exposed to the sample. In this study we show that the combined in-situ UV-vis/ ED-XAS stopped-flow setup is ideally suited to check the influence of X-ray radiation on catalytic systems. To our best knowledge, this is the second example in which the combination of two in-situ techniques in one experimental setup has an additional advantage besides providing experimental evidence for the existence or absence of catalytically active species or reaction intermediates. The first example constituted the use of in-situ UV-vis spectroscopy to quantify in-situ Raman spectra of a catalytic solid under working conditions without the use of an internal standard..$^{15}$

\section{Conclusions}

The results presented show an additional advantage of combining two different in-situ characterization techniques in one reaction setup. A combination of the in-situ UV-vis and ED-XAS techniques can be useful in the study of reaction mechanisms in the homogeneous phase. Besides that, the one technique can be used to check the influence of the other technique on the sample. In this specific case it allowed the 
probing of the effect of the X-ray beam on a copper sample. Using this setup, evidence for a temperature effect of the X-ray beam on the sample was found. This caused an increase in the speed of the catalysis occurring in the cuvette. Besides that, proof for a reducing influence of the X-ray beam on the sample was found. It was shown that the extent of the effect could be influenced by the choice of the copper-precursor salt and that the speed of the reduction process is influenced by the flux of the X-rays on the sample and the halide concentration. It is very important to realize that the observed phenomena not only occur under "severe" X-ray exposure (undulator source, white beam), but also are observed (although at different time scales) under "more mild" X-ray exposure (bending magnet, monochromatic $\mathrm{X}$-rays). This work illustrates the advantage of a second technique, such as in-situ UV-vis spectroscopy, to evaluate the effect of synchrotron radiation used to measure in-situ XAFS on systems in aqueous solution. Finally, we would like to stress that this study does not imply that all synchrotron measurements are prone to radiation damage. Merely, we would like to draw attention to an often-underestimated phenomenon in the literature, which may lead to wrong interpretations of the obtained in-situ XAFS data and consequently incorrect conclusions on the catalytic reaction cycle.

Acknowledgment. Financial support from NWO-van der Leeuw, NWO-VIDI, NWO-VICI, and the Dutch National Research School Combination-Catalysis (NRSC-C) is gratefully acknowledged. The European Synchrotron Radiation Facility (ESRF, Grenoble, France) is acknowledged for the provision of synchrotron radiation facilities. We thank S. Pascarelli, S. G. Fiddy, G. Guilera of beamline ID24 (ESRF), and W. Bras and S. Nikitenko of DUBBLE (BM26A, ESRF) for their help and discussion during the experiments. We thank Hans Meeldijk (Utrecht University) for making the TEM images. Isabel Arends (Delft University of Technology) and Patrick Gamez (Leiden University) are thanked for discussions on the copper/bipyridine system.

\section{References and Notes}

(1) In-situ Spectroscopy of Catalysts; Weckhuysen, B. M., Ed.; American Scientific Publishers: Stevenson Ranch, 2004.
(2) In-situ Spectroscopy in Heterogeneous Catalysis; Haw, J. F., Ed.; Wiley-VCH: Weinheim, 2002.

(3) Lamberti, C.; Prestipino, C.; Bonino, F.; Capello, L.; Bordiga, S.; Spoto, G.; Zecchina, A.; Moreno, S. D.; Cremaschi, B.; Garilli, M.; Marsella, A.; Carmello, D.; Vidotto, S.; Leofanti, G. Angew. Chem., Int. Ed. 2002, 41, 2341.

(4) Lamberti, C.; Bordiga, S.; Bonino, F.; Prestipino, C.; Berlier, G.; Capello, L.; D’Acapito, F.; Xamena, F. X. L. i.; Zecchina, A. Phys. Chem. Chem. Phys. 2003, 5, 4502 .

(5) Newton, M. A.; Dent, A. J.; Diaz-Moreno, S.; Fiddy, S. G.; Evans, J. Angew. Chem., Int. Ed. 2002, 41, 2587.

(6) Clausen, B. S.; Topsoe, H.; Frahm, R. Adv. Catal. 1998, 42, 315.

(7) Sankar, G.; Thomas, J. M.; Catlow, C. R. A. Top. Catal. 2000, 10, 255.

(8) Sankar, G.; Thomas, J. M. Top. Catal. 1999, 8, 1.

(9) Grunwaldt, J.-D.; Clausen, B. S. Top. Catal. 2002, 18, 37.

(10) Tromp, M.; Sietsma, J. R. A.; Bokhoven, J. A. v.; Stijdonck, G. P. A. v.; Haaren, R. J. v.; Eerden, A. M. J. v. d.; Leeuwen, P. W. N. v.; Koningsberger, D. C. Chem. Commun. 2003, 128.

(11) Tromp, M. Developments of Time-Resolved XAFS Spectroscopy Techniques; Ph.D. Thesis, Utrecht University, 2004.

(12) Nijhuis, T. A.; Tinnemans, S. J.; Visser, T.; Weckhuysen, B. M. Phys. Chem. Chem. Phys. 2003, 5, 4361.

(13) Weckhuysen, B. M. Phys. Chem. Chem. Phys. 2003, 5, 4351.

(14) Nijhuis, T. A.; Tinnemans, S. J.; Visser, T.; Weckhuysen, B. M. Chem. Eng. Sci. 2004, 59, 5487.

(15) Tinnemans, S. J.; Kox, M. H. F.; Nijhuis, T. A.; Visser, T.; Weckhuysen, B. M. Phys. Chem. Chem. Phys 2005, 7, 211.

(16) Bruckner, A. Catal. Rev. Sci. Eng. 2003, 45, 97.

(17) Bruckner, A. Chem. Commun. 2001, 2122.

(18) Bruckner, A. Phys. Chem. Chem. Phys. 2003, 5, 4461.

(19) Grunwaldt, J.-D.; Caravati, M.; Hannemann, S.; Baiker, A. Phys. Chem. Chem. Phys. 2004, 6, 3037.

(20) Bowie, B. T.; Chase, D. B.; Griffiths, P. R. Appl. Spectrosc. 2000, $54,200 \mathrm{~A}$.

(21) Beetz, T. Soft X-ray diffraction imaging with and without lenses and radiation damage studies; Ph.D. Thesis, State University of New York, 2004.

(22) Li, C.; Stair, P. C. Catal. Today 1997, 33, 353

(23) Gamez, P.; Arends, I. W. C. E.; Sheldon, R. A.; Reedijk, J. Adv. Synth. Catal. 2004, 346, 805.

(24) Kau, L.-S.; Spira-Solomon, D. J.; Penner-Hahn, J. E.; Hodgson, K. E.; Solomon, E. I. J. Am. Chem. Soc. 1987, 109, 6433.

(25) Lever, A. B. P. Inorganic Electronic Spectroscopy, 2nd ed.; Elsevier Science B. V.: Amsterdam, 1984.

(26) Beetz, T.; Jacobsen, C. J. Synchrotron Radiat. 2002, 10, 280.

(27) Jayanetti, S.; Mayanovic, R. A.; Anderson, A. J.; Bassett, W. A.; Chou, I.-M. J. Chem. Phys. 2001, 115, 954.

(28) Jonah, C. D. Radiat. Res. 1995, 144, 141 